\title{
Cortical grey matter sodium accumulation is associated with disability and secondary progressive disease course in relapse-onset multiple sclerosis
}

\author{
Wallace J Brownlee, ${ }^{1}$ Bhavana Solanky, ${ }^{1}$ Ferran Prados, ${ }^{1,2}$ Marios Yiannakas, ${ }^{1}$ \\ Patricia Da Mota, ${ }^{1}$ Frank Riemer, ${ }^{3}$ Manuel Jorge Cardoso, ${ }^{2}$ Sebastian Ourselin, ${ }^{2}$ \\ Xavier Golay, ${ }^{4}$ Claudia Gandini Wheeler-Kingshott, ${ }^{1,5,6}$ Olga Ciccarelli ${ }^{1,7}$
}

\begin{abstract}
- Additional material is published online only. To view please visit the journal online (http://dx.doi.org/10.1136/ jnnp-2018-319634)
\end{abstract}

For numbered affiliations see end of article.

Correspondence to DrWallace J Brownlee, Department of Neuroinflammation, Queen Square Multiple Sclerosis Centre, London WC1N 3BG, UK; w.brownlee@ucl.ac.uk

Received 13 September 2018 Revised 13 December 2018 Accepted 8 February 2019 Published Online First 4 April 2019

Check for updates

(C) Author(s) (or their employer(s)) 2019. No commercial re-use. See rights and permissions. Published by BMJ.

To cite: Brownlee WJ, Solanky B, Prados F, et al. J Neurol Neurosurg Psychiatry 2019:90:755-760

\section{ABSTRACT}

Objective Sodium $\left({ }^{23} \mathrm{Na}\right)-\mathrm{MRI}$ is an emerging imaging technique to investigate in vivo changes in tissue viability, reflecting neuroaxonal integrity and metabolism. Using an optimised ${ }^{23} \mathrm{Na}-\mathrm{MRI}$ protocol with smaller voxel sizes and improved tissue contrast, we wanted to investigate whether brain total sodium concentration (TSC) is a biomarker for long-term disease outcomes in a cohort of patients with relapse-onset multiple sclerosis (MS), followed from disease onset.

Methods We performed a cross-sectional study in 96 patients followed up 15 years after a clinically isolated syndrome (CIS) and 34 healthy controls. Disease course was classified as CIS, relapsing-remitting MS or secondary progressive MS (SPMS). We acquired ${ }^{1} \mathrm{H}-\mathrm{MRI}$ and ${ }^{23} \mathrm{Na}-\mathrm{MRI}$ and calculated the TSC in cortical grey matter (CGM), deep grey matter, normal-appearing white matter (WM) and WM lesions. Multivariable linear regression was used to identify independent associations of tissue-specific TSC with physical disability and cognition, with adjustment for tissue volumes.

Results TSC in all tissues was higher in patients with MS compared with healthy controls and patients who remained CIS, with differences driven by patients with SPMS. Higher CGM TSC was independently associated with Expanded Disability Status Scale $\left(R^{2}=0.26\right)$, timed 25-foot walk test $\left(R^{2}=0.23\right)$, 9-hole peg test $\left(R^{2}=0.23\right)$, Paced Auditory Serial Addition Test $\left(R^{2}=0.29\right)$, Symbol Digit Modalities Test $\left(R^{2}=0.31\right)$ and executive function $\left(R^{2}=0.36\right)$ test scores, independent of grey matter atrophy.

Conclusions Sodium accumulation in CGM reflects underlying neuroaxonal metabolic abnormalities relevant to disease course heterogeneity and disability in relapseonset MS. TSC and should be considered as an outcome measure in future neuroprotection trials.

\section{INTRODUCTION}

Energy failure is thought to be central to the pathophysiology of multiple sclerosis (MS) and may provide a link between demyelination and neurodegeneration, ${ }^{1}$ the two pathological hallmarks of MS. Following inflammatory demyelination, compensatory electrophysiological changes occur in demyelinated axons in order to preserve function, at least in the short-term, with upregulation and redistribution of sodium channels in order to maintain conduction. ${ }^{2}$ The high energy requirements of the $\mathrm{Na}^{+} / \mathrm{K}^{+}$-ATPase pump, potentially compounded by primary mitochondrial dysfunction in $\mathrm{MS},{ }^{3}$ overwhelm neuronal ATP production, resulting in failure of the $\mathrm{Na}^{+} / \mathrm{K}^{+}$-ATPase pump and intracellular sodium accumulation. Increased intracellular sodium concentration triggers a cascade of events that ultimately results in neuroaxonal loss, the major substrate for disease progression in MS.

Sodium $\left({ }^{23} \mathrm{Na}\right)$ MRI is an emerging imaging technique able to quantify brain tissue sodium concentration in vivo, providing information on tissue viability, reflecting neuroaxonal integrity and metabolic function. ${ }^{45}$ The measured total sodium concentration (TSC) using ${ }^{23} \mathrm{Na}-\mathrm{MRI}$ reflects a composite of intracellular sodium (10-15 mM) and extracellular sodium $(\sim 140 \mathrm{mM})$. Previous ${ }^{23} \mathrm{Na}-\mathrm{MRI}$ studies have found evidence of increased TSC in white matter (WM) lesions and normal-appearing tissues in MS, ${ }^{6-10}$ reflecting either increased intracellular sodium, expansion of the extracellular space (due to neuroaxonal loss) or both. In cross-sectional studies, increases in TSC are most marked in progressive $\mathrm{MS}^{8}$ and in patients with greater physical disability ${ }^{78}$ and cognitive impairment. ${ }^{10}$

${ }^{23} \mathrm{Na}-\mathrm{MRI}$ is challenging due to the lower tissue concentrations of sodium compared with hydrogen and a lower signal-to-noise ratio. Previous studies have been affected by hardware/software limitations of clinical scanners and have acquired ${ }^{23} \mathrm{Na}$ MRI with large voxel sizes $\left(4 \times 4 \times 4 \mathrm{~mm}^{3}\right),{ }^{6-10}$ thereby increasing partial volume contamination, especially from cerebrospinal fluid (CSF), which contains a higher sodium concentration $(\sim 140$ $\mathrm{mM}$ ) than tissues. We recently optimised a ${ }^{23} \mathrm{Na}$ MRI protocol with smaller voxel size $\left(3 \times 3 \times 3 \mathrm{~mm}^{3}\right.$ vs $4 \times 4 \times 4 \mathrm{~mm}^{3}$ in previous studies) and a $3 \mathrm{D}$-cones acquisition trajectory technique with improved tissue contrast, signal-to-noise ratio and reproducibility, in clinically acceptable scanning times. ${ }^{11}$

We applied this optimised ${ }^{23} \mathrm{Na}-\mathrm{MRI}$ protocol in a cross-sectional study involving a unique and homogeneous cohort of patients followed over $\sim 15$ years following presentation with a clinically isolated syndrome (CIS). The aims of the study were: (1) to investigate the relationship of tissue TSC with long-term disease course in a group of patients well-matched for disease onset and (2) to 


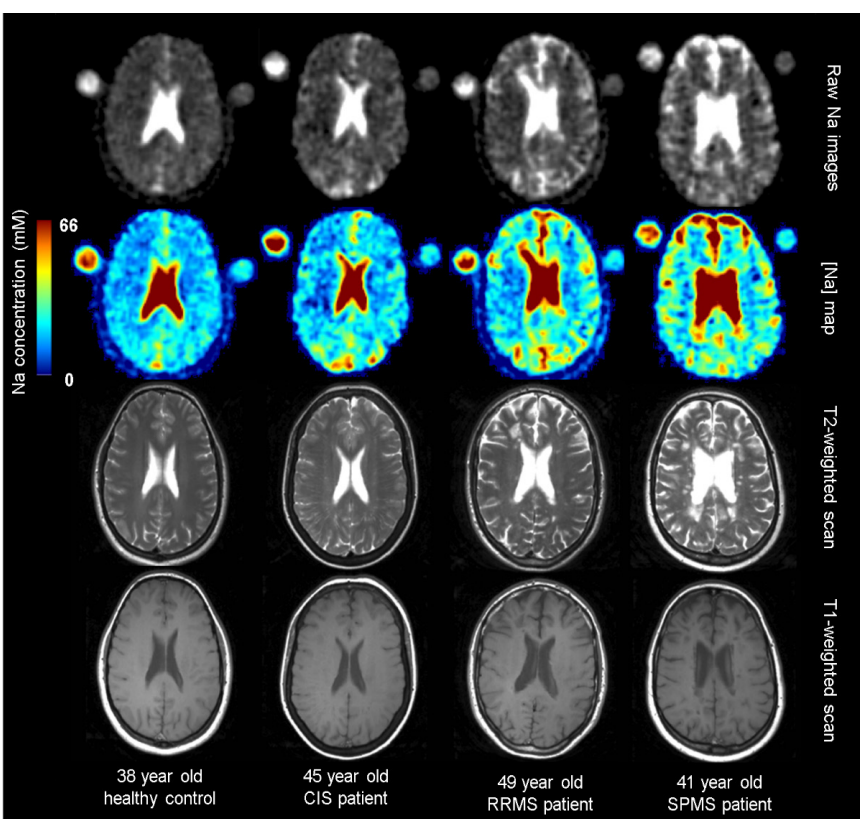

Figure 1 Raw sodium images, sodium concentration maps and ${ }^{1} \mathrm{H}$ T2weighted and T1-weighted images (obtained using the 32 channel head coil), in healthy controls and patients with CIS, RRMS and SPMS. CIS, clinically isolated syndrome; RRMS, relapsing-remitting multiple sclerosis; SPMS, secondary progressive multiple sclerosis.

investigate the relationship of tissue TSC with physical disability and cognitive impairment.

\section{METHODS}

\section{Patients}

This is a cross-sectional study carried out at the last visit of a longitudinal clinical-MRI study. Briefly, patients were initially recruited into the study within 3 months of a CIS and invited to return for scheduled clinical and MRI follow-up, irrespective of clinical status. ${ }^{12}$ The clinical and MRI assessments presented here were done $\sim 15$ years after CIS. We diagnosed MS using the McDonald 2010 criteria at follow-up. ${ }^{13}$ Disease course at $\sim 15$ years was classified as CIS, relapsing-remitting MS (RRMS) and secondary progressive MS (SPMS). ${ }^{14}$ We retrospectively reviewed the clinical details and MRI scans of patients diagnosed as CIS in light of the revised McDonald 2017 criteria and no additional patients were identified as having MS.

We assessed physical disability using the Expanded Disability Status Scale (EDSS), timed 25-foot walk test (TWT) and 9-hole peg test (9HPT). ${ }^{15} 16$ The TWT raw scores were transformed into an inverse to determine walking speed (in feet/second) and 9HPT times were transformed into a $Z$-score using normative values. ${ }^{16}$ Cognition was assessed using: (1) tests of verbal and visual memory from the Adult Memory and Information Processing Battery; ${ }^{17}$ (2) tests of information processing speed, the Paced Auditory Serial Addition Test (PASAT) ${ }^{16}$ and the Symbol Digit Modalities Test (SDMT) ${ }^{18}$ and (3) tests of executive function, the Hayling and Brixton tests. ${ }^{19}$ Premorbid intellectual function was estimated using the National Adult Reading Test (NART). ${ }^{20}$ The raw test scores for each of the cognitive tests were transformed into a $z$-score using published age-matched normative data. ${ }^{16-19}$ Patients with a $z$-score $\leq-2$ were considered impaired on that test. Self-reported fatigue was measured using the Fatigue Severity Scale. ${ }^{21}$ None of the patients had a relapse or received treatment with corticosteroids within 3 months of the clinical assessment and MRI.

A group of healthy control subjects with no known neurological disorder underwent the same MRI protocol. All subjects provided written informed consent and the study was approved by the institutional Research Ethics Committee.

\section{MRI acquisition}

The MRI scans were obtained on the same $3.0 \mathrm{~T}$ scanner (Achieva, Phillips Healthcare Systems). Using a 32-channel receiver head coil the following ${ }^{1} \mathrm{H}-\mathrm{MRI}$ scans were obtained: (i) a proton density(PD)/T2-weighted fast-spin multi-echo scan for identification of T2-hyperintense lesions; (ii) a 2D T1-weighted spin echo scan for identification of T1-hypointense lesions and (iii) a magnetisation-prepared $1 \mathrm{~mm}^{3}$ isotropic 3D T1-weighted turbo field echo scan for tissue segmentation. The 32-channel head coil was changed to a ${ }^{23} \mathrm{Na} \mathrm{TX} / \mathrm{RX}$ volume body coil (RAPID Biomedical, Germany) and the subject was returned to the scanner with two calibration agar phantoms placed in a predefined position, containing $\mathrm{NaCl}$ with a sodium concentration of $40 \mathrm{mM}$ and $80 \mathrm{mM}$, respectively. The $\mathrm{NaCl}$ concentration in the calibration phantoms was chosen to encompass the range of physiological values expected in brain parenchymal tissues. Following the ${ }^{23} \mathrm{Na}-\mathrm{MRI}$ with the subject remaining in the same position, a low-resolution ${ }^{1} \mathrm{H}-\mathrm{PD} / \mathrm{T} 2$-weighted scan was obtained using the body coil, for registration purposes. Details of the MRI acquisition protocol are shown in online supplementary table 1 . Representative images from a healthy control subject and each of the patient groups studied are shown in figure 1 .

\section{Image analysis}

A single rater (WJB) manually outlined T2-hyperintense and T1-hypointense WM lesions on using a semi-automated edgefinding tool (JIM6.0, Xinapse Systems, UK) to obtain T2 lesion volume (T2LV) and T1 lesion volume (T1LV). The T2-hyperintense lesion masks were coregistered to the 3D T1-weighted scan. WM lesions were filled using a patch-based lesion filling technique. $^{22}$ Brain extraction and probabilistic tissue segmentation of the lesion-filled 3D-T1w scans were done using Geodesic Information Flows ${ }^{23}$ to create cortical grey matter (CGM), deep grey matter (DGM) and normal-appearing WM (NAWM) masks. The brain parenchymal fraction, grey matter fraction (GMF) and WM fraction (WMF) were calculated, by dividing the tissue-specific volumes by the total intracranial volume.

A fully-automated image analysis pipeline was used to determine the TSC in tissues from the sodium images. ${ }^{24}$ The signal intensity in calibration phantoms was used as a reference to quantify the TSC on a voxel-by-voxel basis. ${ }^{6} \mathrm{~A}$ series of registration steps were then used and concatenated to quantify TSC in each tissue type: (1) the sodium scan was registered to the PD/T2-weighted scan obtained using the body coil; (2) the PD/ T2-weighted scan obtained using the body coil was registered to the PD/T2-weighed scan obtained using the 32-channel head coil and (3) the PD/T2-weighted scan obtained using the 32-channel head coil was registered to the 3D T1-weighted scan. Tissue mask were resampled using a point-spread-function scaling factor into sodium space to calculate the TSC (in $\mathrm{mM}$ ) for each tissue. ${ }^{25}$ Using the probabilistic masks partial volume correction was performed for each voxel. ${ }^{8}$ Finally, using a voxel-wise partition-based correction method, we removed CSF contamination. ${ }^{8}$ 


\section{Statistical analysis}

All clinical, ${ }^{1} \mathrm{H}-\mathrm{MRI}$ and ${ }^{23} \mathrm{Na}-\mathrm{MRI}$ quantitative data are presented as mean (SD) unless otherwise stated.

Differences in clinical measures between groups were compared using univariable linear regression, except for EDSS, which was compared using the non-parametric Wilcoxon rank-sum test. Differences in ${ }^{1} \mathrm{H}$-MRI findings between groups were compared using univariable linear regression, with age and sex included as covariates when comparing brain volumetric measures. Differences in TSC in CGM, DGM, NAWM and lesions between groups was compared using univariable linear regression using GMF or WMF as a covariate depending on the tissue type being examined.

Multivariable linear regression was used to identify independent associations between tissue-specific TSC and clinical measures in all patients and in the subgroup with MS. Significant univariable predictor variables were entered into the model and removed by stepwise backward manual elimination of variables with $p>0.08$. Each of the omitted variables was then tested in the final models. Because EDSS is not normally distributed, the final regression model was checked using non-parametric bias-corrected and accelerated bootstrap with 1000 replicates to confirm associations. Tissue-specific brain atrophy was included as a covariate in all models, and the NART was included as a covariate in models examining associations with cognition. Age, sex and disease duration had no material effect on regression coefficients and were not retained as covariates.

Statistical analyses were done using SPSS 21. Significance is reported at the level of $\mathrm{p}<0.05$.

\section{RESULTS}

Demographic and clinical characteristics

A total of 130 subjects were studied: 34 healthy controls and 96 patients from the CIS follow-up study (table 1). Over a mean follow-up period of 14.7 years (range 11.2-19.2 years), 78 (81\%) patients developed MS and 18 (19\%) remained CIS. Among the patients with MS, disease course was classified as RRMS in 65 and SPMS in 13 patients. Twenty (26\%) patients with MS were receiving (or had received) disease-modifying therapy.

Compared with the patients who remained CIS at 15 years, the patients with MS had more physical disability, worse performance on cognitive tests (with the exception of visual memory) and greater fatigue $(\mathrm{p}<0.05$ for all comparisons). The patients with SPMS had worse performance on all clinical measures compared with the patients with RRMS ( $p<0.05$ for all comparisons), except verbal memory.

\section{${ }^{1} \mathrm{H}-\mathrm{MRI}$ findings}

The GMF and WMF were similar in patients who remained CIS and health controls (table 2). We observed significant differences in the patients with MS in GMF (adjusted difference -0.011 $(95 \% \mathrm{CI}-0.016$ to 0.006$), \mathrm{p}<0.001)$ and WMF (adjusted difference -0.009 [95\% CI -0.015 to 0.003$], \mathrm{p}=0.002$ ) compared with healthy controls, and significant differences in the patients with MS in GMF (adjusted difference -0.008 [95\% CI -0.014 to 0.002], $\mathrm{p}=0.010$ ) and WMF (adjusted difference -0.012 [95\% CI -0.020 to 0.004], $p=0.002$ ) compared with the patients with CIS (table 2). Within the MS group, the patients with SPMS showed significant differences in GMF (adjusted difference -0.009 [95\% CI -0.016 to 0.001], $\mathrm{p}=0.021$ ), WMF (adjusted difference -0.010 [95\%CI -0.020 to 0.001$], \mathrm{p}=0.028), \mathrm{T} 2 \mathrm{LV}(17.97$ vs $9.81 \mathrm{~mL}, \mathrm{p}=0.026)$ and T1LV (5.87 vs $1.90 \mathrm{~mL}, \mathrm{p}<0.001)$ compared with patients with RRMS (table 2).

\section{${ }^{23} \mathrm{Na}-\mathrm{MRI}$ findings}

TSC in CGM, DGM and NAWM was similar in the patients who remained CIS and healthy controls (table 2). In all patients with MS together, there were significant differences in TSC in CGM (adjusted difference $2.12 \mathrm{mM}$ [95\% CI 0.66 to 3.57], $\mathrm{p}=0.005$ ), DGM (adjusted difference $1.90 \mathrm{mM}[95 \%$ CI 0.33

Table 1 Demographic characteristics of healthy controls and patients grouped by clinical status at 15 years

\begin{tabular}{|c|c|c|c|c|c|}
\hline & \multirow[b]{2}{*}{$\begin{array}{l}\text { Healthy controls } \\
(n=34)\end{array}$} & \multirow[b]{2}{*}{$\begin{array}{l}\text { Patients with CIS } \\
(\mathrm{n}=18)\end{array}$} & \multicolumn{3}{|l|}{ Patients withMS } \\
\hline & & & $\begin{array}{l}\text { All MS } \\
(n=78)\end{array}$ & $\begin{array}{l}\text { RRMS } \\
(n=65)\end{array}$ & $\begin{array}{l}\text { SPMS } \\
(n=13)\end{array}$ \\
\hline Age, years & $35.5(10.1)$ & $49.0(7.2)$ & $47.0(7.5)$ & $46.8(7.6)$ & $47.8(7.8)$ \\
\hline Female, n (\%) & $23(66)$ & $12(67)$ & $59(86)$ & $50(77)$ & $9(69)$ \\
\hline Disease duration, years & & $14.5(2.1)$ & $14.7(2.4)$ & $14.6(2.4)$ & $15.0(2.8)$ \\
\hline Disease-modifying therapy, $\mathrm{n}(\%)$ & & $0(0)$ & $0(0)$ & $18(28)$ & $4(31)$ \\
\hline 9-Hole peg test, $z$ score & & $0.78(0.70)$ & $0.23(0.91) \dagger$ & $0.50(0.61)$ & $-1.16(0.82) \ddagger$ \\
\hline Verbal memory, $z \mid \mathrm{n}$ impaired (\%) & & $0.21(0.60) \mid 0(0)$ & $-0.32(0.58)^{*} \mid 1(1)$ & $-0.27(0.54) \mid 1(2)$ & $-0.59(0.74) \mid 0(0)$ \\
\hline Visual memory, $z \mid \mathrm{n}$ impaired (\%) & & $0.24(0.49) \mid 0(0)$ & $-0.06(0.65) \mid 2(3)$ & $-0.01(0.63) \mid 1(2)$ & $-0.35(0.76) \neq \mid 1(8)$ \\
\hline PASAT, $z \mid \mathrm{n}$ impaired (\%) & & $0.21(0.68) \mid 0(0)$ & $-0.48(1.09) \dagger \mid 7(9)$ & $-0.32(0.99) \mid 3(5)$ & $-1.32(1.25) \neq \mid 4(30)$ \\
\hline SDMT, $z \mid \mathrm{n}$ impaired (\%) & & $0.31(0.90) \mid 0(0)$ & $-0.65(1.38)^{*} \mid 11(14)$ & $-0.34(1.18) \mid 3(5)$ & $-2.12(1.38) \ddagger \mid 8(62)$ \\
\hline
\end{tabular}

All data presented as mean (SD) unless otherwise indicated. Impairment on cognitive tests was defined as a $z$ score $\leq 2.0$ SD below published normative data.

${ }^{*} \mathrm{P}<0.01$ compared with CIS.

$+\mathrm{P}<0.05$ compared with CIS.

$\ddagger \mathrm{P}<0.01$ compared with RRMS.

$\S \mathrm{P}<0.05$ compared with RRMS.

CIS, clinically isolated syndrome; EDSS, Expanded Disability Status Scale; MS, multiple sclerosis; PASAT, Paced Auditory Serial Addition Test; RRMS, relapsing-remitting MS; SDMT, Symbol Digit Modalities Test; SPMS, secondary progressive MS. 
Table 2 Total sodium concentrations in healthy controls and subjects grouped by clinical status at 15 years

\begin{tabular}{|c|c|c|c|c|c|}
\hline & \multirow{2}{*}{$\begin{array}{l}\text { Healthy } \\
\text { controls } \\
(n=34)\end{array}$} & \multirow{2}{*}{$\begin{array}{l}\text { Patients } \\
\text { with CIS } \\
(n=18)\end{array}$} & \multicolumn{3}{|c|}{ Patients with MS } \\
\hline & & & $\begin{array}{l}\text { All MS } \\
(n=78)\end{array}$ & $\begin{array}{l}\text { RRMS } \\
(n=65)\end{array}$ & $\begin{array}{l}\text { SPMS } \\
(n=13)\end{array}$ \\
\hline $\begin{array}{l}\text { Brain parenchymal } \\
\text { fraction }\end{array}$ & $\begin{array}{l}0.768 \\
(0.009)\end{array}$ & $\begin{array}{l}0.767 \\
(0.008)\end{array}$ & $\begin{array}{l}0.747^{*}, \dagger \\
(0.028)\end{array}$ & $\begin{array}{l}0.751 \\
(0.018)\end{array}$ & $\begin{array}{l}0.7319 \\
(0.028)\end{array}$ \\
\hline $\begin{array}{l}\text { Grey matter } \\
\text { fraction }\end{array}$ & $\begin{array}{l}0.458 \\
(0.009)\end{array}$ & $\begin{array}{l}0.453 \\
(0.006)\end{array}$ & $\begin{array}{l}0.445^{*}, \ddagger \\
(0.014)\end{array}$ & $\begin{array}{l}0.447 \\
(0.012)\end{array}$ & $\begin{array}{l}0.4389 \\
(0.014)\end{array}$ \\
\hline $\begin{array}{l}\text { White matter } \\
\text { fraction }\end{array}$ & $\begin{array}{l}0.310 \\
(0.011)\end{array}$ & $\begin{array}{l}0.314 \\
(0.010)\end{array}$ & $\begin{array}{l}0.302^{*}, \dagger \\
(0.016)\end{array}$ & $\begin{array}{l}0.303 \\
(0.016)\end{array}$ & $\begin{array}{l}0.293 \text { व } \\
(0.016)\end{array}$ \\
\hline $\begin{array}{l}\text { T2 lesion volume, } \\
\mathrm{ml}\end{array}$ & & & $\begin{array}{l}11.08 \\
(12.00)\end{array}$ & $\begin{array}{l}9.81 \\
(11.60)\end{array}$ & $\begin{array}{l}17.979 \\
(12.28)\end{array}$ \\
\hline $\begin{array}{l}\text { T1 lesion volume, } \\
\mathrm{ml}\end{array}$ & & & $\begin{array}{l}2.54 \\
(3.52)\end{array}$ & $\begin{array}{l}1.90 \\
(2.91)\end{array}$ & $\begin{array}{l}5.879 \\
(4.53)\end{array}$ \\
\hline \multicolumn{6}{|l|}{${ }^{23} \mathrm{Na} \mathrm{MRI}$} \\
\hline $\begin{array}{l}\text { Cortical grey } \\
\text { matter }\end{array}$ & $\begin{array}{l}40.63 \mathrm{mM} \\
(2.33)\end{array}$ & $\begin{array}{l}40.68 \mathrm{mM} \\
(1.74)\end{array}$ & $\begin{array}{l}42.82 \mathrm{mM}^{*} \\
(3.53)\end{array}$ & $\begin{array}{l}42.30 \mathrm{mM} \\
(3.29)\end{array}$ & $\begin{array}{l}45.45 \mathrm{mM}^{* *} \\
(3.69)\end{array}$ \\
\hline Deep grey matter & $\begin{array}{l}34.83 \mathrm{mM} \\
(2.79)\end{array}$ & $\begin{array}{l}36.13 \mathrm{mM} \\
(1.69)\end{array}$ & $\begin{array}{l}36.69 \mathrm{mM} \S \\
(3.74)\end{array}$ & $\begin{array}{l}36.14 \mathrm{mM} \\
(3.47)\end{array}$ & $\begin{array}{l}39.47 \mathrm{mM}^{* *} \\
(3.98)\end{array}$ \\
\hline $\begin{array}{l}\text { Normal-appearing } \\
\text { white matter }\end{array}$ & $\begin{array}{l}32.03 \mathrm{mM} \\
(3.44)\end{array}$ & $\begin{array}{l}32.92 \mathrm{mM} \\
(2.43)\end{array}$ & $\begin{array}{l}34.85 \mathrm{mM} \S \\
(4.05)\end{array}$ & $\begin{array}{l}34.43 \mathrm{mM} \\
(3.95)\end{array}$ & $\begin{array}{l}36.95 \mathrm{mM} \\
(4.04)\end{array}$ \\
\hline \multicolumn{6}{|l|}{$\begin{array}{l}\text { White matter } \\
\text { lesions }\end{array}$} \\
\hline $\begin{array}{l}\text { All T2- } \\
\text { hyperintense } \\
\text { lesions }\end{array}$ & & & $\begin{array}{l}45.58 \mathrm{mM} \\
(8.53)\end{array}$ & $\begin{array}{l}44.27 \mathrm{mM} \\
(8.27)\end{array}$ & $\begin{array}{l}51.99 \mathrm{mM} 9 \\
(6.92)\end{array}$ \\
\hline $\begin{array}{l}\text { T1-isointense } \\
\text { lesions }\end{array}$ & & & $\begin{array}{l}43.93 \mathrm{mM} \\
(5.83)\end{array}$ & $\begin{array}{l}42.87 \mathrm{mM} \\
(7.04)\end{array}$ & $\begin{array}{l}49.30 \mathrm{mM} 9 \\
(5.83)\end{array}$ \\
\hline $\begin{array}{l}\text { T1-hypointense } \\
\text { lesions }\end{array}$ & & & $\begin{array}{l}52.08 \mathrm{mM} \\
(7.43)\end{array}$ & $\begin{array}{l}51.02 \mathrm{mM} \\
(11.56)\end{array}$ & $\begin{array}{l}57.45 \mathrm{mM} \\
(7.43)\end{array}$ \\
\hline
\end{tabular}

All data presented as mean (SD).

${ }^{*} \mathrm{P}<0.01$ compared with healthy controls.

$+\mathrm{P}<0.01$ compared with CIS;

$\ddagger \mathrm{P}<0.05$ compared with CIS.

$\S \mathrm{P}<0.05$ compared with healthy controls.

$\mathbb{\| P}<0.01$ compared with RRMS.

${ }^{*} \mathrm{P}<0.05$ compared with RRMS

CIS, clinically isolated syndrome; MS, multiple sclerosis; RRMS, relapsing-remitting

MS; SPMS, secondary progressive MS.

to 3.47], $\mathrm{p}=0.018$ ) and NAWM (adjusted difference 1.99 $\mathrm{mM}$ [95\% CI 0.45 to 3.53], $\mathrm{p}=0.012$ ) compared with healthy controls (table 2). These changes were driven by patients with SPMS (table 2).
In patients with MS, there were significant differences in TSC in T2-hyperintense lesions compared with NAWM (adjusted difference $11.42 \mathrm{mM}$ [95\% CI 9.53 to 13.3], $\mathrm{p}<0.001$ ), and T1-hypointense compared with T1-isointense WM lesions (adjusted difference $8.14 \mathrm{mM}$ [95\% CI 5.12 to 11.17], $\mathrm{p}<0.001)$. Significant differences in TSC in T2-hyperintense lesions in the patients with SPMS compared with patients with RRMS (adjusted difference $7.54 \mathrm{mM}$ [95\% CI 2.61 to 12.46], $\mathrm{p}=0.003$ ), mainly driven by the difference in TSC in T1-isointense lesions in the SPMS group (adjusted difference $6.58 \mathrm{mM}$ [95\% CI 2.29 to 10.87 ], $\mathrm{p}=0.003$ ).

\section{Associations between tissue sodium concentrations and disability}

CGM sodium concentration was independently associated with EDSS $\left(\mathrm{R}^{2}=0.26\right)$, TWT $\left(\mathrm{R}^{2}=0.23\right)$ and 9HPT $\left(\mathrm{R}^{2}=0.23\right)$ (table 3 ). CGM sodium concentration was also independently associated with PASAT $\left(\mathrm{R}^{2}=0.29\right)$, SDMT $\left(\mathrm{R}^{2}=0.31\right)$ and the Brixton test $\left(\mathrm{R}^{2}=0.36\right)$. No independent association was seen with tissue-specific TSC and memory tests, the Hayling test and fatigue.

The multivariable linear regression analyses were repeated after excluding patients who remained CIS (table 3), first to confirm findings in the MS group and second to examine associations between TSC in WM lesions with disability (none of the patient with CIS at 15 years had typical demyelinating WM lesions). In the MS-only model $(n=78)$, CGM and T1-hypointense lesion TSC were associated with EDSS $\left(\mathrm{R}^{2}=0.25\right)$, TWT $\left(\mathrm{R}^{2}=0.24\right)$ and 9HPT $\left(\mathrm{R}^{2}=0.32\right)$. The associations with the cognitive tests was similar: CGM TSC was associated with PASAT $\left(\mathrm{R}^{2}=0.29\right)$, SDMT $\left(\mathrm{R}^{2}=0.31\right)$ and the Brixton test $\left(\mathrm{R}^{2}=0.38\right)$ and no association was seen with memory, the Hayling test or fatigue.

\section{DISCUSSION}

In a unique, homogeneous cohort of patients with relapse-onset MS, we found a consistent association of CGM TSC with disease course, physical disability and cognition when assessed cross-sectionally 15 years after disease onset. We aimed to overcome some of the key limitations of early applications of ${ }^{23} \mathrm{Na}-\mathrm{MRI}$ in MS, including: (1) an optimised ${ }^{23} \mathrm{Na}-\mathrm{MRI}$ protocol with the smaller voxel sizes (effective voxel size $27 \mathrm{~mm}^{3}$ vs $64 \mathrm{~mm}^{3}$ in earlier studies), to reduce the impact of partial volume effects from CSF; (2) a new postprocessing pipeline with a cutting-edge

Table 3 Statistically significant associations between tissue-specific total sodium concentrations and clinical measures

\begin{tabular}{|c|c|c|c|c|c|c|c|c|c|c|}
\hline \multirow[b]{2}{*}{ Clinical measure } & \multicolumn{5}{|c|}{ All patients $(n=96)$} & \multicolumn{5}{|l|}{ Patients with MS ( $n=78)$} \\
\hline & TSC & $\beta$ & $95 \% \mathrm{Cl}$ & $p$ & $R^{2}$ & TSC & $\beta$ & $95 \% \mathrm{Cl}$ & $p$ & $R^{2}$ \\
\hline EDSS & CGM & 0.174 & 0.061 to 0.287 & 0.003 & 0.26 & $\begin{array}{l}\text { CGM } \\
\text { T1-hypointense lesions }\end{array}$ & $\begin{array}{l}0.128 \\
0.020\end{array}$ & $\begin{array}{l}0.010 \text { to } 0.246 \\
0.000 \text { to } 0.041 \\
\left(0.002 \text { to } 0.037^{*} \text { ) }\right.\end{array}$ & $\begin{array}{l}0.035 \\
0.055 \\
\left(0.023^{*}\right)\end{array}$ & 0.25 \\
\hline Walking speed & CGM & -0.006 & -0.010 to 0.002 & 0.003 & 0.23 & $\begin{array}{l}\text { CGM } \\
\text { T1-hypointense lesions }\end{array}$ & $\begin{array}{l}-0.005 \\
-0.001\end{array}$ & $\begin{array}{l}-0.009 \text { to } 0.001 \\
-0.002 \text { to } 0.0005\end{array}$ & $\begin{array}{l}0.023 \\
0.032\end{array}$ & 0.24 \\
\hline$z$ 9HPT & CGM & -0.096 & -0.148 to 0.051 & 0.001 & 0.23 & $\begin{array}{l}\text { CGM } \\
\text { T1-hypointense lesions }\end{array}$ & $\begin{array}{l}-0.091 \\
-0.014\end{array}$ & $\begin{array}{l}-0.152 \text { to } 0.030 \\
-0.025 \text { to } 0.004\end{array}$ & $\begin{array}{l}0.004 \\
0.008\end{array}$ & 0.32 \\
\hline$z$ PASAT & CGM & -0.105 & -0.177 to 0.032 & 0.005 & 0.29 & CGM & -0.101 & -0.180 to 0.023 & 0.012 & 0.29 \\
\hline z SDMT & CGM & -0.156 & -0.246 to 0.066 & 0.001 & 0.31 & CGM & -0.143 & -0.240 to 0.046 & 0.005 & 0.31 \\
\hline z Brixton test & CGM & -0.067 & -0.120 to 0.014 & 0.014 & 0.36 & CGM & -0.066 & -0.118 to 0.015 & 0.013 & 0.38 \\
\hline
\end{tabular}

${ }^{*}$ Bootstrap $\mathrm{Cl}$ and $\mathrm{p}$ value.

9HPT, 9 Hole peg test; CGM, cortical grey matter; EDSS, Expanded Disability Status Scale; PASAT, Paced Auditory Serial Addition Test; SDMT, Symbol Digit Modalities Test; TSC, total sodium concentration. 
tissue segmentation algorithm ${ }^{23}$ and (3) adjustment of statistical analysis for tissue-specific volume loss.

We found a higher TSC in both CGM and DGM in patients with MS compared with healthy controls. In WM, a gradient was seen in patients with MS with the highest TSC in T1-hypointense lesions, followed by T1-isointense lesions and then NAWM. These differences were mainly driven by patients with SPMS, who showed higher TSC in these regions compared with RRMS, suggesting a greater degree of neuroaxonal metabolic dysfunction, neuroaxonal loss or both in SPMS. These findings are consistent with a greater extent of brain atrophy and microstructural damage detected using ${ }^{1} \mathrm{H}$-MRI in SPMS. ${ }^{26} 27$ In contrast, no increase in tissue-specific TSC was seen in the patients who remained CIS after 15 years. We also found no difference in brain volume measurements in the patients who remained CIS compared with healthy controls. These findings are supported by previous studies showing that patients who remain CIS in the long-term do not have detectable structural ${ }^{2627}$ or metabolic ${ }^{28}$ abnormalities seen in people with MS, and MRI findings are similar to healthy controls.

Independent associations were observed between ${ }^{23} \mathrm{Na}-\mathrm{MRI}$ abnormalities and clinical impairment. TSC in CGM was associated with EDSS, walking speed and upper limb dexterity. Previous studies have also reported an association of total grey matter TSC with measures of physical disability. ${ }^{6-8}$ CGM TSC was also associated with performance on tests of information processing speed and executive function. CGM pathology is recognised as being a major substrate for both physical disability and cognitive impairment, ${ }^{29}$ including ${ }^{1} \mathrm{H}$-MRI detected grey matter lesions, ${ }^{30}$ atrophy ${ }^{27}$ and microstructural damage. ${ }^{26}$ Although we observed a consistent association of CGM TSC with clinical measures, the associations were only moderate. This highlights that while brain ${ }^{23} \mathrm{Na}$-MRI is sensitive to the detection of neuroaxonal metabolic changes and/or tissue loss, other disease mechanisms that contribute to disability and cognitive performance are not captured by this technique (eg, spinal cord damage, changes in structural and functional connectivity).

Sodium channel blockade has been proposed as a neuroprotective strategy in MS based on results of animal studies showing that sodium channel blocking agents reduced axonal loss in experimental autoimmune encephalomyelitis models. ${ }^{31}$ These observations are supported by a recent phase II showing a neuroprotective effect of phenytoin on retinal nerve fibre layer thinning acute optic neuritis. ${ }^{32}$ In view of our findings (and previous studies highlighting the sensitivity of ${ }^{23} \mathrm{Na}$-MRI to measures of clinical impairment) ${ }^{4-8}$ and the reproducibility of this technique (including in multicentre studies), ${ }^{33}$ TSC should be added as an exploratory endpoint to neuroprotection trials that aim to preserve neuroaxonal viability using sodium channel blockade. We have included ${ }^{23} \mathrm{Na}-\mathrm{MRI}$ as an endpoint in the Protective Role of Oxcarbazepine in Multiple Sclerosis (PROXIMUS) study - a phase IIa randomised controlled trial of oxcarbamazepine in people with relapsing MS with worsening disability while receiving disease-modifying therapies (https://clinicaltrials.gov/ ct2/show/NCT02104661).

Some possible limitations of this work should be noted. The healthy control group were younger than the patient group. However, we found no relationship between age and tissue-specific TSC, in keeping with previous studies. ${ }^{8}$ It is unlikely that the increased TSC in patients with MS is due to older age, particularly since there was no difference between healthy control and patients with CIS. Although we studied a large cohort (this study is largest application of ${ }^{23} \mathrm{Na}-\mathrm{MRI}$ in MS to date), the number of patients with SPMS who were scanned as part of the 15 year follow-up was small $(n=13)$. Despite the small number clear differences were seen, particularly in grey matter, between the SPMS and RRMS group, findings that are consistent with a previous study with a larger sample of patients with SPMS. ${ }^{8}$

Although ${ }^{23} \mathrm{Na}-\mathrm{MRI}$ is a promising new imaging technique with the potential to provide information on tissue viability, including neuroaxonal integrity and function, there are a number of technical challenges and limitations in previous studies using $3 \mathrm{~T}$ clinical scanners. The concentration of ${ }^{23} \mathrm{Na}$ in tissues is significantly lower than ${ }^{1} \mathrm{H}$ with a much lower signal-to-noise ratio. Consequently the voxel size required is significantly larger, typically $4 \times 4 \times 4 \mathrm{~mm}^{3} \cdot{ }^{6-10}$ A larger voxel size increases the risk of partial volume effects, especially from CSF, which contains a much higher sodium concentration than tissues $(\sim 140 \mathrm{mM})$. We took a number of steps to reduce the effects of partial volume, representing an innovative methodology. First, the scans were acquired using an optimised ${ }^{23} \mathrm{Na}$-MRI protocol that included a higher resolution (nominal $3 \times 3 \times 3 \mathrm{~mm}^{3}$ ) and more efficient sampling of $k$-space using a $3 \mathrm{D}$-cones technique. ${ }^{11}$ These changes have been shown to improve tissue contrast, increase signal-to-noise ratio and provide a better point spread function with voxel sizes closer to the nominal value. ${ }^{11}$ Second, the image-analysis pipeline included a partition-based method to correct for CSF contamination. Third, the tissue masks were resampled to sodium space using a point spread function scaling factor. ${ }^{25}$ Finally, as an additional precaution all of the analyses were adjusted for tissue-specific atrophy (GMF, WMF or both), which has not been done in previous studies.

TSC in tissues represents a composite of intracellular and extracellular sodium. Tissue sodium accumulation in MS could be due to an increase in intracellular sodium due to axonal metabolic dysfunction, an increase in extracellular sodium due to expansion of the extracellular space arising from neuroaxonal loss or both. A number of approaches have been described for measuring intracellular sodium concentration in vivo. A recent study at $7 \mathrm{~T}$ used triple quantum filtering to exploit the differences in the correlation time of sodium nuclei in intracellular and extracellular space to effectively separate them. ${ }^{34}$ This technique allows quantification of TSC, intracellular sodium concentration and the intracellular sodium volume fraction (a surrogate measure of the extracellular sodium). This approach has been applied in a study of 19 patients with RRMS. Compared with healthy controls, the patients with RRMS showed a significant increase in intracellular sodium concentration and decrease in intracellular sodium volume fraction. ${ }^{33}$ These findings suggest that both an increase in intracellular sodium concentration and a reduction in the intracellular volume (due to axonal loss) contribute to the increase in TSC in MS.

\section{CONCLUSION}

${ }^{23} \mathrm{Na}$-MRI detects pathological abnormalities that are relevant to long-term disease progression, physical disability and cognitive impairment in relapse-onset MS. Metabolic abnormalities in CGM may be an important mechanism contributing to disease progression and disease course heterogeneity in relapse-onset MS. ${ }^{23} \mathrm{Na}-\mathrm{MRI}$ is an emerging outcome measure for novel neuroprotection interventions in MS and has started to be translated into neuroprotection trial design.

\section{Author affiliations}

Queen Square Multiple Sclerosis Centre, UCL Institute of Neurology, London, United Kingdom 
${ }^{2}$ Translational Imaging Group, Centre for Medical Image Computing (CMIC), Department of Medical Physics and Bioengineering, University College London, London, United Kingdom

${ }^{3}$ Department of Radiology, University of Cambridge School of Clinical Medicine, Cambridge, United Kingdom

${ }^{4}$ Department of Brain Repair and Rehabilitation, UCL Institute of Neurology, London, United Kingdom

5BrainMRI 3T Research Centre, IRCCS Mondino Foundation, Pavia, Italy

${ }^{6}$ Departmentof Brain and Behavioural Sciences, University of Pavia, Pavia, Italy ${ }^{7}$ National Institute for Health Research (NIHR) University College London Hospitals Biomedical Research Centre, London, United Kingdom

Contributors WJB contributed to study concept/design, analysis and interpretation of data, statistical analysis and drafting manuscript. BS contributed to study concept/ design, analysis and interpretation of data and manuscript revision. FP contributed to study concept/design, analysis and interpretation of data and manuscript revision. MY contributed to data acquisition, analysis and interpretation and manuscript revision. PDM contributed to analysis and interpretation of data and manuscript revision. FR contributed to study concept/design, analysis and interpretation of data and manuscript revision. MJC contributed to data analysis and manuscript revision. SO contributed to data analysis and manuscript revision XG contributed to study concept/design and manuscript revision. CW-K contributed to study concept/design, interpretation of data and manuscript revision. OC obtained funding and contributed to study concept/design, manuscript revision and provided study supervision.

Funding This study was funded by the United Kingdom MS Society and the Neurological Foundation of New Zealand and supported by the National Institute for Health Research (NIHR) University College London Hospitals (UCLH) Biomedical Research Centre.

Disclaimer WJB has received speaker fees from Merck Serono, Sanofi Genzyme and Roche. BS, FP, MY, PDM, FR, MJC, SO and XG report no financial disclosures relevant to this manuscript. OC serves as a consultant for Novartis, Teva, Roche, Genzyme and Biogen Idec.

Competing interests WJB has received speaker fees from Merck Serono, Sanofi Genzyme and Roche. BS, FP, MY, PDM, FR, MJC, SO and XG report no financial disclosures relevant to this manuscript. OC serves as a consultant for Novartis, Teva, Roche, Genzyme and Biogen Idec.

Patient consent for publication Not required.

Provenance and peer review Not commissioned; externally peer reviewed.

\section{REFERENCES}

1 Lassmann H, van Horssen J, Mahad D. Progressive multiple sclerosis: pathology and pathogenesis. Nat Rev Neurol 2012;8:647-56.

2 Craner MJ, Newcombe J, Black JA, et al. Molecular changes in neurons in multiple sclerosis: altered axonal expression of Nav1.2 and Nav1.6 sodium channels and $\mathrm{Na}+/ \mathrm{Ca} 2+$ exchanger. Proceedings of the National Academy of Sciences 2004:101:8168-73.

3 Dutta R, McDonough J, Yin X, et al. Mitochondrial dysfunction as a cause of axonal degeneration in multiple sclerosis patients. Ann Neurol 2006:59:478-89.

4 Petracca M, Fleysher L, Oesingmann N, et al. Sodium MRI of multiple sclerosis. NMR Biomed 2016:29:153-61.

5 Gandini Wheeler-Kingshott CAM, Riemer F, Palesi F, et al. Challenges and perspectives of quantitative functional sodium imaging (fNal). Front Neurosci 2018;12.

6 Inglese M, Madelin G, Oesingmann N, et al. Brain tissue sodium concentration in multiple sclerosis: a sodium imaging study at 3 tesla. Brain 2010;133:847-57.

7 Zaaraoui W, Konstandin S, Audoin B, et al. Distribution of brain sodium accumulation correlates with disability in multiple sclerosis: a cross-sectional 23Na MR imaging study. Radiology 2012;264:859-67.
8 Paling D, Solanky BS, Riemer F, et al. Sodium accumulation is associated with disability and a progressive course in multiple sclerosis. Brain 2013;136:2305-17.

9 Maarouf A, Audoin B, Konstandin S, et al. Topography of brain sodium accumulation in progressive multiple sclerosis. Magn Reson Mater Phy 2014;27:53-62.

10 Maarouf A, Audoin B, Pariollaud F, et al. Increased total sodium concentration in gray matter better explains cognition than atrophy in MS. Neurology 2017;88:289-95.

11 Riemer F, Solanky BS, Stehning C, et al. Sodium (23Na) ultra-short echo time imaging in the human brain using a 3D-Cones trajectory. Magn Reson Mater Phy 2014;:27:35-46.

12 Brownlee WJ, Altmann DR, Alves Da Mota P, et al. Association of asymptomatic spinal cord lesions and atrophy with disability 5 years after a clinically isolated syndrome. Mult Scler 2017;23:665-74.

13 Polman CH, Reingold SC, Banwell B, et al. Diagnostic criteria for multiple sclerosis: 2010 revisions to the McDonald criteria. Ann Neurol 2011;69:292-302.

14 Lublin FD, Reingold SC,National Multiple Sclerosis Society (USA) Advisory Committee on Clinical Trials of New Agents in Multiple Sclerosis* . Defining the clinical course of multiple sclerosis: results of an international survey. Neurology 1996;46:907-11.

15 Kurtzke JF. Rating neurologic impairment in multiple sclerosis: an expanded Disability Status Scale (EDSS). Neurology 1983;33:1444.

16 Cutter GR, Baier ML, Rudick RA, et al. Development of a multiple sclerosis functional composite as a clinical trial outcome measure. Brain 1999;122:871-82.

17 Coughlan A, Hollows A. The adult memory and information processing battery. Leeds: St James Univeristy Hospital, 1985.

18 Smith A. Symbol digit modalities test (SDMT) manual (revised. Los Angeles: Western Psychological Services, 1982

19 Burgess P, Shallice T. The hayling and Brixton tests. Bury St Edmunds: Thames Valley Test Company, 1997.

20 Nelson $\mathrm{H}$. The national adult reading test. Windsor, 1982.

21 Krupp LB, LaRocca NG, Muir-Nash J, et al. The fatigue severity scale. Application to patients with multiple sclerosis and systemic lupus erythematosus. Arch Neurol 1989;46:1121-3.

22 Prados F, Cardoso MJ, Kanber B, et al. A multi-time-point modality-agnostic patchbased method for lesion filling in multiple sclerosis. Neuroimage 2016;139:376-84

23 Cardoso MJ, Modat M, Wolz R, et al. Geodesic information flows: Spatially-Variant graphs and their application to segmentation and fusion. IEEE Trans Med Imaging 2015;34:1976-88.

24 Prados F, Solanky BS, Alves Da Mota P, et al. Automatic sodium maps reconstruction using PatchMatch algorithm for phantom detection. ISMRM 2016.

25 Cardoso MJ, Modat M, Vercauteren T, et al. Scale factor point spread function matching: beyond Aliasing in image resampling. MICCAI 2015:675-83.

26 Fisniku LK, Altmann DR, Cercignani M, et al. Magnetization transfer ratio abnormalities reflect clinically relevant grey matter damage in multiple sclerosis. Mult Scler 2009;15:668-77.

27 Fisniku LK, Chard DT, Jackson JS, et al. Gray matter atrophy is related to long-term disability in multiple sclerosis. Ann Neurol. 2008;64:247-54.

28 Kapeller P, Brex PA, Chard D, et al. Quantitative 1H MRS imaging 14 years after presenting with a clinically isolated syndrome suggestive of multiple sclerosis. Mult Scler 2002:8:207-10.

29 Geurts JJG, Barkhof F. Grey matter pathology in multiple sclerosis. Lancet Neurol 2008;7:841-51.

30 Calabrese M, Poretto V, Favaretto A, et al. Cortical lesion load associates with progression of disability in multiple sclerosis. Brain 2012;135:2952-61.

31 Bechtold DA, Kapoor R, Smith KJ. Axonal protection using flecainide in experimental autoimmune encephalomyelitis. Ann Neurol 2004;55:607-16.

32 Raftopoulos R, Hickman SJ, Toosy A, et al. Phenytoin for neuroprotection in patients with acute optic neuritis: a randomised, placebo-controlled, phase 2 trial. Lancet Neurol 2016:15:259-69.

33 McHugh DJ, Riemer F, Lewis D, et al. Standardisation and quantification of 23Na-MRI: repeatability and reproducibility off sodium imaging. Joint Annual Meeting ISMRMESMRMB 2018

34 Petracca M, Vancea RO, Fleysher $\mathrm{L}$, et al. Brain intra- and extracellular sodium concentration in multiple sclerosis: a 7 T MRI study. Brain 2016;139:795-806. 